\title{
Lesión corneal por picadura de abeja en paciente con VIH y ojo único funcional. Reporte de un caso
}

\section{Corneal bee sting in an HIV patient with a single functional eye. Case report}

\author{
Jossefat A. Godina-Morales*, Efraín Romo-García, Karen A. García-Medina y \\ Alejandro Ruelas-Barreras \\ Servicio de Oftalmología, Hospital Civil de Culiacán, Centro de Investigación y Docencia de Ciencias de la Salud, Culiacán, Sinaloa, México
}

\section{Resumen}

Objetivo: Las picaduras de abeja resultan en distintas reacciones oftalmológicas, y por eso se debe individualizar el tratamiento en cada caso, dependiendo de su presentación clínica. Caso clínico: Varón de 45 años, portador del virus de la inmunodeficiencia humana y con ojo único por trauma ocular derecho, que acude a revisión por picadura de abeja 24 horas antes en el ojo izquierdo. Fue necesario realizar lavado de cámara anterior para la extracción del aguijón, ya que no se presentó mejoría clínica tras el manejo conservador. Conclusiones: Las picaduras de himenópteros en oftalmología son poco documentadas, y aunado a las características clínicas previas del paciente, fue importante decidir el tratamiento más conveniente. La respuesta clínica desencadenada por la picadura de abejas en los ojos es muy variable entre personas, por lo que constituye un reto para el oftalmólogo. La intervención quirúrgica demostró ser muy útil para la recuperación visual en este caso, la cual se mantiene hasta 7 meses después.

Palabras clave: Abeja. Córnea. Monocular. Veneno de abeja. VIH.

\begin{abstract}
Purpose: Bee stings cause different reactions in the eye, so each treatment must be individualized. Case report: $A$ 45-year-old male patient, HIV positive, one-eyed due to a right ocular trauma, suffered a corneal bee sting on the left eye. We performed surgery to extract the stinger and anterior chamber washout, since the patient did not show improvement after conservative treatment. Conclusions: Bee stings in ophthalmology are uncommon, and due to the previous clinical situation of the patient, it was important to decide the best treatment for him. The clinical response after a bee sting is very variable between patients, so it is a challenge for the ophthalmologist. Our surgical approach was very effective in this case, since the patient showed a visual recovery without relapse 7 months after the injury.
\end{abstract}

Key words: Bee. Cornea. Monocular. Bee Venom. HIV.

Correspondencia:

*Jossefat A. Godina-Morales

Álvaro Obregón, 1422

Tierra Blanca

Fecha de recepción: 20-02-2020

Fecha de aceptación: 12-06-2020

C.P. 80030, Culiacán Rosales, Sin., México

E-mail: Jagm1613@ hotmail.es

DOI: 10.24875/RMO.M20000138
Disponible en internet: 12-01-2021

Rev Mex Oftalmol. 2021;95(3):129-132

www.rmo.com.mx 0187-4519/@ 2020 Sociedad Mexicana de Oftalmología. Publicado por Permanyer. Este es un artículo open access bajo la licencia CC BY-NC-ND (http://creativecommons.org/licenses/by-nc-nd/4.0/). 


\section{Introducción}

Los cuerpos extraños intraoculares son situaciones comunes en oftalmología, generalmente debidas a traumatismos, pero la incidencia de heridas oculares secundarias a picadura de abeja son presentaciones menos habituales. La picadura de abeja puede afectar no solo de forma local, sino también desatando una respuesta sistémica que puede involucrar otras estructuras del globo ocular, relativamente lejanas al sitio de la lesión. La respuesta puede ser leve, moderada 0 grave, además de conllevar un riesgo in feccioso ${ }^{1}$. Existe poca evidencia en oftalmología sobre cómo se deben tratar estos casos y sus complicaciones.

\section{Caso clínico}

Se trata de un varón de 45 años, portador del virus de la inmunodeficiencia humana $(\mathrm{VIH})$, en tratamiento con efavirenz $600 \mathrm{mg}$, emtricitabina $200 \mathrm{mg}$ y tenofovir $300 \mathrm{mg}$ (Atripla $\AA$ ), una vez cada 24 horas, desde hace 10 años, refiriendo última carga viral como indetectable y conteo de CD4 de 329 células $/ \mathrm{mm}^{3}$ hace 2 meses, quien tiene además ojo único por lesión del nervio óptico no especificada secundaria a un traumatismo ocular derecho en un accidente automovilístico 20 años antes. Acude a consulta al Hospital Civil de Culiacán refiriendo picadura de abeja en el ojo izquierdo de 24 horas de evolución. A su llegada refiere dolor, baja visión y sensación de cuerpo extraño en el ojo izquierdo. A la exploración física se encuentra el ojo derecho con pupila arrefléctica, conjuntiva eurémica, córnea transparente, cámara formada, iris íntegro, cristalino transparente, retina aplicada, mácula respetada, vasos sanos, nervio óptico pálido y aspecto atrófico; el ojo izquierdo con hiperemia conjuntival de tres cruces, córnea opaca, edematosa, con lesión blanquecina en M2 captante de fluoresceína, estrías en la membrana de Descemet y celularidad en la cámara anterior de dos cruces, cristalino con LOCS III NO2 NC2 y fondo de ojo no valorable por opacidad de medios. La presión intraocular (PIO) es de $10 \mathrm{mmHg}$. Agudeza visual: ojo derecho no percepción de luz, ojo izquierdo 20/60 que no mejora con agujero estenopeico (Figs. 1 y 2).

Se inició tratamiento con ciprofloxacino al $0.3 \%$ cada 6 horas, hialuronato de sodio sin conservadores al $0.15 \%$ cada 2 horas, tropicamida/fenilefrina $(8 \mathrm{mg} / 50 \mathrm{mg} / \mathrm{ml})$ como ciclopléjico cada 8 horas, prednisolona suspensión al $1 \%$ cada 4 horas y loratadina $10 \mathrm{mg}$ por vía oral cada 12 horas.

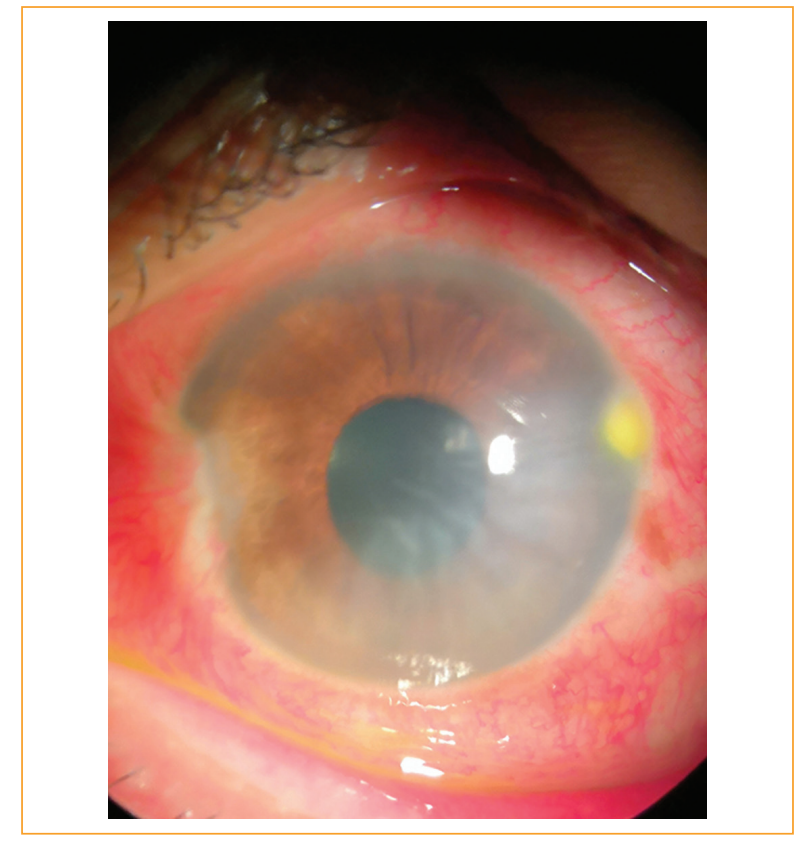

Figura 1. Fotografía inicial de segmento anterior en la que se observa hiperemia conjuntival con edema en la córnea de predomino temporal e inferior, así como lesión en M2 correspondiente al sitio de la picadura.

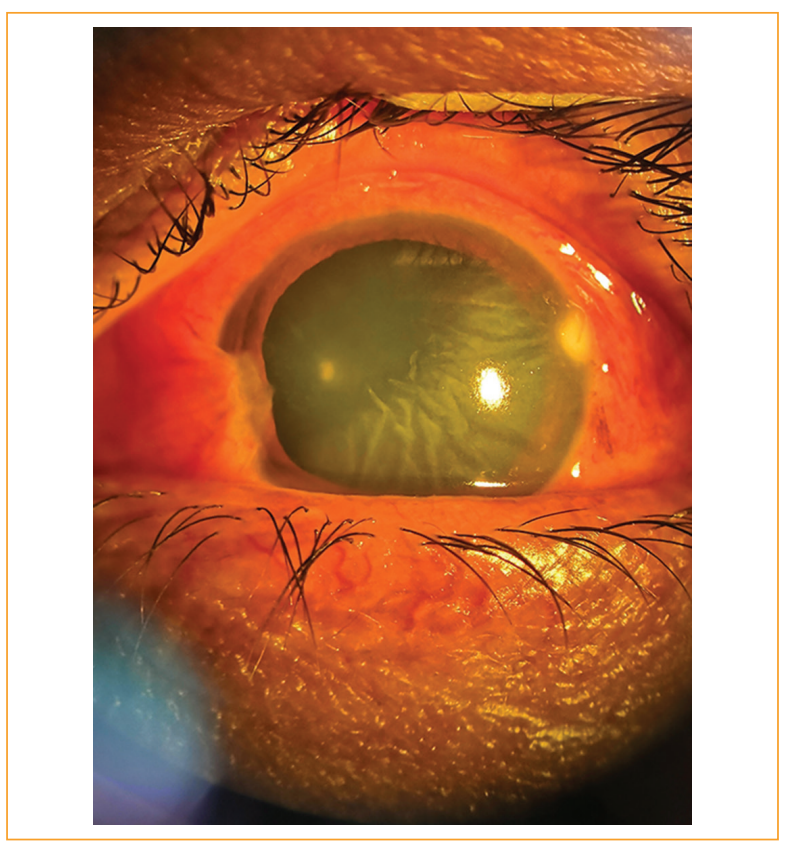

Figura 2. Fotografía de segmento anterior con pupila dilatada, sin aparente involucro del cristalino.

Se cita al paciente a la consulta externa 72 horas después y se observa una leve disminución de la 


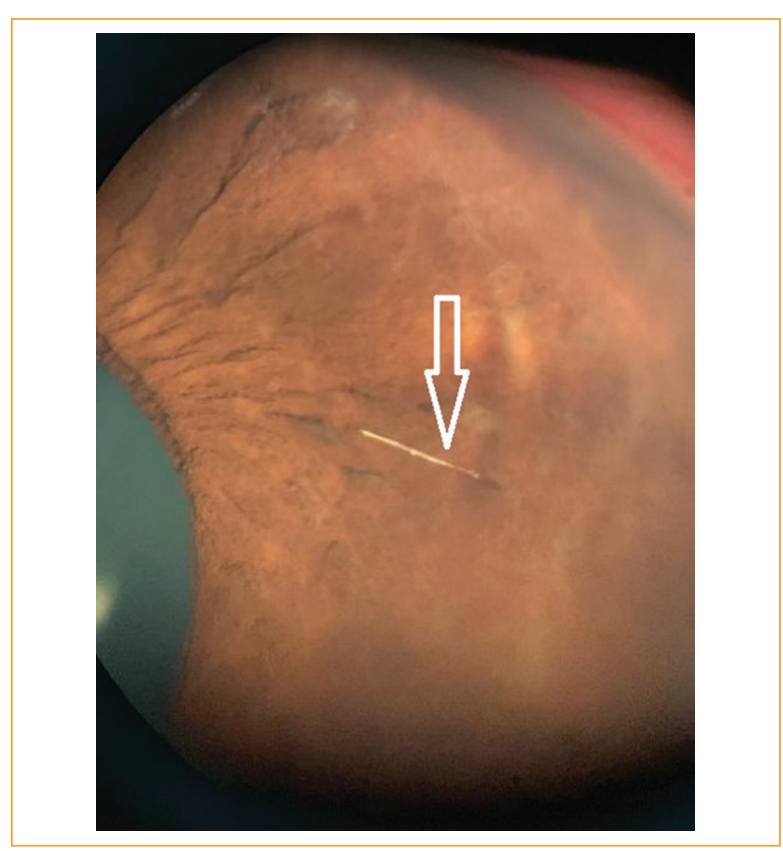

Figura 3. Aguijón de abeja sobre el iris en la cámara anterior.

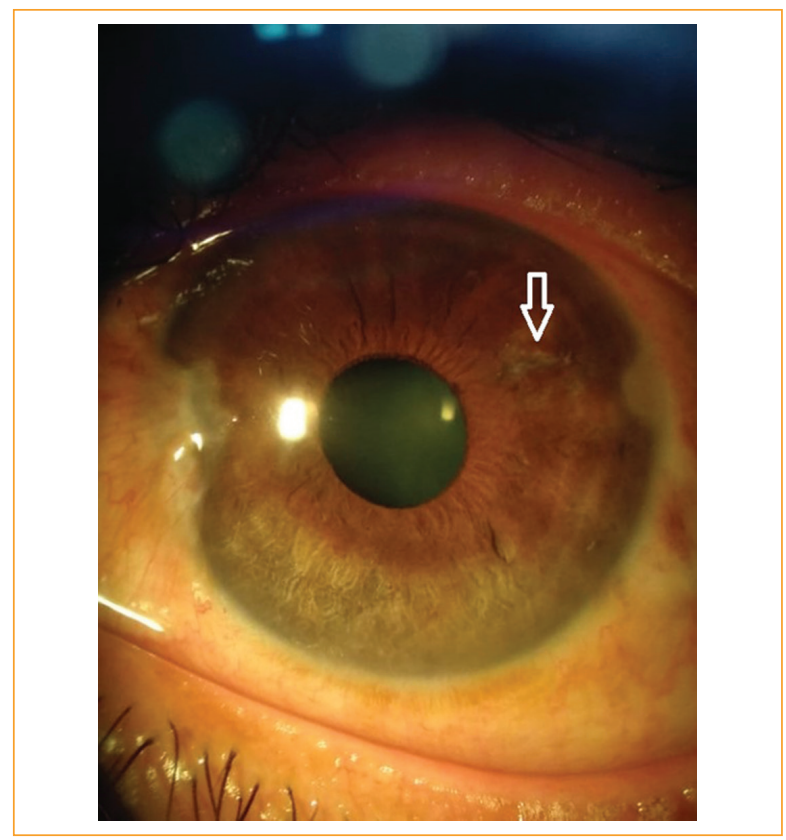

Figura 4. Fotografía de segmento anterior a las 24 horas del posoperatorio, en la que se observa ligera atrofia en M2, donde estaba el aguijón.

opacidad y del edema corneal, por lo que se puede valorar con mayor detalle y se encuentra una lesión corneal en M2 con opacidad de predominio inferior, estrías en la membrana de Descemet, PIO de $10 \mathrm{mmHg}$ e iris con atrofia sectorial en M2, lográndose observar un resto de aguijón sobre el iris (Fig. 3). Fondo de ojo no valorable por opacidad de medios. Agudeza visual: ojo izquierdo 20/50 que no mejoraba, por lo que 24 horas después se decide realizar lavado de cámara anterior y extracción de cuerpo extraño.

Se realizó la extracción del aguijón mediante lavado de cámara anterior, realizando una incisión corneal con cuchillete de $2.8 \mathrm{~mm}$ en M2. Se forma cámara con viscoelástico viscodispersivo y se localiza el fragmento de aguijón en el estroma iridiano, procediendo a su retiro usando pinza utrata. Posteriormente se lava la cámara anterior con solución salina balanceada y se hidratan los bordes de la herida corneal, finalizando el procedimiento. No se realizó cultivo del material extraído. A las 24 horas posoperatorias, el paciente se encuentra con mejoría de su sintomatología, agudeza visual 20/20, reflejos normales, conjuntiva bulbar hiperémica, córnea transparente, cámara formada y amplia, iris íntegro, pupila central, PIO de $10 \mathrm{mmHg}$, fondo de ojo retina aplicada, mácula respetada y excavación 4/10 (Fig. 4).

\section{Discusión}

Es polémico decidir la conducta en pacientes con picaduras de abeja en los ojos, especialmente cuando hay retención del aguijón, ya que se ha demostrado que la permanencia del veneno desencadena reacciones como queratoconjuntivitis, degeneración endotelial, hipopión, glaucoma, catarata, uveítis, vitritis o retinitis ${ }^{1}$. Además, el aguijón en sí es un cuerpo orgánico de origen animal que podría provocar infección local ${ }^{2}$. En este caso, la reacción inflamatoria e inmunitaria parece ser acorde con lo descrito en la literatura, sin que existiera ningún cambio significativo por el estado inmunitario previo, aunque si no se hubiera tomado la conducta quirúrgica quizás habrían aumentado las complicaciones en el paciente dada su inmunosupresión.

La respuesta inmunitaria desencadenada en este tipo de agresiones desata la liberación de toxinas polipeptídicas, como fosfolipasa, hialuronidasa, melitina y apamina, además de mediadores como histamina y dopamina, que se inicia minutos después de la picadura. Se cree que la melitina participa en la formación de cataratas, mientras que la apamina se ha propuesto como causante de neuropatía óptica por sus propiedades neurotóxicas ${ }^{2,3}$. Nuestro paciente se presentó al servicio por baja visual y dolor, secundario a edema y queratitis estromal, síntomas que fueron parcialmente controlados con colirios, pero dada la presencia del aguijón dentro de la cámara anterior y las 
características clínicas dadas por el VIH y el ojo único funcional, se decidió llevar a cabo tratamiento quirúrgico para su extracción con el fin de evitar la aparición de complicaciones, secundario al cual el paciente presentó notable mejoría en la agudeza visual, que se mantiene hasta 7 meses después. Afortunadamente, en este caso no se presentó reacción en el segmento posterior del ojo, lo que lo ayudó a tener una rápida agudeza visual posoperatoria.

Rai, et al. ${ }^{2}$ sugieren sacar inmediatamente el aguijón si este es de fácil acceso y si hay una reacción primaria que involucre el eje visual, aun teniendo en cuenta que la extirpación quirúrgica del aguijón no siempre es exitosa, dada la complejidad por su tamaño y forma, mientras que los pacientes que no cumplen estas características pueden ser tratados de forma conservadora.

En la literatura local hay reportes de casos con conducta expectante a base de esteroide, ciclopléjico y antibiótico, con buen desenlace, aunque con un apego y monitoreo continuo para detectar de manera oportuna cualquier complicación ${ }^{4}$. Es de suma importancia hacer una exploración oftalmológica completa en estos pacientes, que incluya eversión de ambos párpados para evitar pasar por alto una retención de restos en los fondos de saco, ya que pueden condicionar complicaciones a largo plazo ${ }^{5}$.

\section{Conclusiones}

Las picaduras de himenópteros son casos poco comunes en oftalmología, pero es de suma importancia decidir el tratamiento que más beneficie al paciente, ya que la presentación clínica puede variar mucho según la persona. La decisión de extraer o no el aguijón debe ser individualizada en cada caso, dada la idiosincrasia. En nuestro caso eran más las posibles complicaciones con el tratamiento conservador. La intervención quirúrgica resultó muy útil, ya que se evidenció una mejoría en la agudeza visual final, la cual se mantiene hasta 7 meses después del evento.

\section{Conflicto de intereses}

Los autores declaran no tener ningún conflicto de intereses.

\section{Responsabilidades éticas}

Protección de personas y animales. Los autores declaran que para esta investigación no se han realizado experimentos en seres humanos ni en animales.

Confidencialidad de los datos. Los autores declaran que han seguido los protocolos de su centro de trabajo sobre la publicación de datos de pacientes.

Derecho a la privacidad y consentimiento informado. Los autores han obtenido el consentimiento informado de los pacientes y/o sujetos referidos en el artículo. Este documento obra en poder del autor de correspondencia.

\section{Bibliografía}

1. Ekta Rishi PR. Intraocular inflammation in a case of bee sting injury. GMS Ophthalmol. 2018;8:1-5.

2. Rai RR, Gonzalez-Gonzalez LA, Papakostas TD, Siracuse-Lee D, Dunphy R, Fanciullo L, et al. Management of corneal bee sting injuries. Semin Ophthalmol. 2017;32:177-81.

3. Semler-Collery A, Hayek G, Ramadier S, Perone JM. A case of conjunctival bee sting injury with review of the literature on ocular bee stings. Am J Case Rep. 2019;20:1284-9.

4. Álvarez-Félix JR, Palazuelos-Gaxiola M, Cinco-Sánchez A. Lesión corneal causada por picadura de abeja. Rev Med UAS. 2016;6(1):19-21.

5. Bhalerao SA, Singh P, Rani PK, Rathi V. The sting of a honey bee: an unusual sub 